\title{
El mil·lenarisme i la cavalleria a la literatura catalana i europea, medieval i moderna, i la seua expressió a l'obra de Maragall
}

\section{Millenarism and Chivalry in the Catalan and European Medi- eval and Modern Literature, and its Expression in the Mara- gall's Production}

\author{
Salvador Sendra Perelló \\ Centre de Formació de Persones Adultes de l'Ajuntament de Paiporta \\ sendraiperello@gmail.com \\ Recibido: marzo de 2016. Aceptado: mayo de 2016
}

\begin{abstract}
Resum: Existeix una concepció cíclica dels esdeveniments i dels pensaments que es plasma en èpoques de crisis i que la literatura ens trasllada valent-se d'icones adaptades a cada temps. Els documents contenen trets de l'oralitat, recollits en aquest trànsit, que cal destacar. La imatge del cavaller ha evolucionat amb el relat, adaptada per sobreviure al temps i als territoris, des del seu origen laic i bèl-lic fins a la transformació religiosa.
\end{abstract}

Mots clau: Edat Mitjana, cavaller, ermità, comte Arnau, mil·lenarisme.

\begin{abstract}
There is a cyclical perception of events and thoughts which is expressed in times of crisis and which literature captures through icons modeled on each age. During this process vestiges of the oral tradition, worth highlighting, are collected in written documents. The image of the knight has evolved throughout storytelling, adapting to endure over time and place, transforming from its original secular and military role to a religious one.
\end{abstract}

Keywords: Edat Mitjana, cavaller, ermità, comte Arnau, mil·lenarisme.

\section{INTRODUCCIÓ}

La literatura sobreviu a les èpoques més fosques de manera oral i rimada, fet que se sol repetir en cada període d'escassa alfabetització. Les civilitzacions -i 
les persones- entren en etapes orals, de fantasia i de símbols, que arriben fins als nostres dies a partir de documents escrits, recollits en èpoques posteriors, on es plasma el declivi de la racionalitat, tant en el llenguatge com en els continguts. Aquests formats físics, escrits i reeditats en moltes ocasions, contenen elements vinculats als temps pels quals han transitat i que cal entendre per separat.

La imatge del cavaller ha estat evolucionant des de l'època medieval, com tantes altres coses. Aquest humà guerrer es va haver d'adaptar a diferents escenaris per poder sobreviure al llarg dels segles. La seua aparició, la causa un període de crisi i la necessitat humana de sobreviure. No obstant això, les primeres notícies que ens arriben són de temps posteriors on el guerrer laic ja s'ha transformat en religiós.

La gran dificultat a l'hora d'endinsar-nos en les creacions dels mites deriva dels passos previs a la plasmació escrita (Lord 2000: 13). Sobre el text creat, bé en vers, bé en prosa, encara romanen les petjades de cada evolució, barrejades amb aquelles que s'han adquirit al llarg de la travessia per una gran quantitat de territoris, de narradors i d'esdeveniments que hi han aportat una important varietat d'elements. L'evolució de la figura del guerrer s'ha adaptat, progressivament, com ho han fet els textos en què es manifesta, a les vicissituds de cada època i de cada territori. A més, i de forma cíclica, aquesta figura retorna en èpoques concretes i sota altres noms.

Tradicionalment, la història s'explica des d'un punt de vista cíclic quan fem servir el prefix re-per referir-nos a una altra volta: renàixer és tornar a nàixer. Aleshores, l'ús del mot Renaixement per descriure una època que s'emmiralla en un període anterior ens demostra que, tot i la nostra sensació d'avançar de manera lineal, la línia recta és imaginària i que l'ésser humà només la percep de manera intel-lectual, que no natural. Nietzsche ja descrivia l'avançament com un «etern retorn» amb una funció bàsica: la necessitat humana de buscar fonaments.

De la mateixa manera que l'actual visió de la Grècia Clàssica és el resultat de la barreja entre la cultura mediterrània i la indoeuropea, on l'equilibri entre ambdues aportacions és imprescindible per aconseguir entendre el nivell que arribà a assolir, es pot afirmar que el sistema feudal resulta d'una mescla semblant entre els vestigis de l'Imperi i l'aportació bàrbara germànica. El problema de la interpretació de les èpoques prèvies és que les hem de reconstruir a partir dels textos escrits, tant de la lírica com de l'èpica, però, fins a la plasmació de les llegües romances, aquests són llatins i, per tant, allunyats del poble indocte. El període medieval és semblant al grec quan la literatura s'ensorra i allò que se salva i evoluciona és l'oralitat (Nietzsche 2007: 70). El temps passat sempre fou millor en el subconscient col-lectiu, i així es manifesta en els textos (Le Goff 1982: 18 i ss.).

La memòria és fonamental per a entendre l'evolució dels pobles i per cohesionar-los. Al llarg del procés de consolidació, sempre hi ha hagut la referència a èpoques pretèrites, daurades, que han anat empudeint-se amb el transcurs del temps (Lord 2000: 7). Una línia teòrica que se sol donar és la que Borges esquematitza de la següent manera, en referència a la literatura $i$ als seus 
antecedents: oral, poesia i prosa. L'evolució de l'expressió fa valer aquest ordre, on es pot aportar, a la part oral, la particularitat de la cançón ${ }^{1}$.

Al final de l'Imperi Romà s'instaura el monoteisme a l'espai literari -i preliterari. El judaisme i el cristianisme estan basats en la memòria, i aquesta s'edifica sobre la base idíllica del Paradís, als inicis, i amb els patriarques com a guies. Cada traducció és una interpretació que comporta d'una modificació de l'original i, en el procés de revisió dels textos, hi ha la dicotomia entre l'immobilisme del relat acceptat o l'adaptació d'aquest, amb interpretacions i diversitat. El temps i l'experiència ens diuen que hi ha hagut difusió, tant en els textos sagrats com en la resta, en la mateixa mesura que hi ha hagut un procés de creació dels clàssics que arriben fins a nosaltres en què s'ha hagut de destriar entre diferents opcions (Le Goff 1982: 30 i ss.).

En una anàlisi de qualsevol evolució, els elements que cal tenir en compte es poden dividir a partir de dos aspectes bàsics: la tradició prèvia que ha assimilat el text $\mathrm{i}$ les referències, en el seu contingut, a elements que ha adquirit, paulatinament, al llarg del seu recorregut (Lord 2000: 5). A l'hora d'esbrinar la figura del guerrer que ens arriba mitjançant els textos, i la contraposició d'aquest personatge amb els estudis que ens aporten els historiadors, entenem que hi ha l'evolució. L'ús de les figures que romanen en el subconscient col-lectiu, a l'hora de difondre un missatge o de fonamentar un sistema social anacrònic, també és un element a tenir en compte, ja que la memòria recerca en el passat, així com en l'imaginari col-lectiu (Lord 2000: 6).

La Chanson de Roland ens ofereix una interessant perspectiva sobre la transformació del relat perquè reflecteix una gran transformació en el trànsit des del succés històric de l'escaramussa dels Pirineus (Riquer 1952: 18-19), fins a la seua versió definitiva plasmada en el manuscrit d'Oxford. Les gestes dels soldats de Carlemany succeïren vora dos-cents anys abans de la seua primera compilació, feta per un monjo, en llatí, però la batalla descrita en la Chanson de Roland va ocórrer tres-cents anys abans del text més vell de què hi ha referència (Riquer 1952: 16-37). D'aquesta realitat es pot deduir que l'epopeia francesa segueix el procés natural que s'inicia en un fet concret $i$ es difon a partir del mite del poble, creador, indocte, ingenu i espontani, alhora que transmet la vertadera poesia popular com a creació col-lectiva, impersonal i anònima. Per tant, en aquestes dues línies es pot interpretar el final d'un procés de vora cinc-cents anys (Riquer 1952: $37 \mathrm{i}$ ss).

Le Goff afirma que l'heroi no existeix sinó en el cant (Le Goff: 1982: 156) de tradició oral, i que evoluciona fins a la novel·la, d'esperit urbà, allunyada de les rimes i de les fórmules de memorització. La novel-la és l'evidència de l'ocàs de la cavalleria perquè és un gènere urbà i íntim, allunyat de la tradició i de la línia de transmissió que s'estira des de la cantinel-la (Riquer 1952: 38 i ss.).

${ }^{1}$ La investigació de Borges se centra en la literatura germànica i, a partir de l'evolució d'aquesta, extrau les conclusions i les generalitza a la resta de literatures (Borges 1966). 


\section{L'EVOLUCIÓ TEMPORAL DEL GUERRER}

La crisi del final de l'Imperi dugué associada violència i mancança d'ètica fins que desembocà en un sistema de protecció de territoris gestionat per militars mercenaris. El desmembrament de l'Imperi s'observa tant des de l'abandó de les vies de comunicació, que féu que els territoris més allunyats de la metròpoli esdevingueren difícils de governar, com des de l'empobriment de l'idioma, agredit per la influència de substrats i adstrats que l'afeblien com a lligam territorial, alhora que aportaven una important dosi d'identitat a la perifèria (Le Goff 1999: 15 i ss.).

Amb les estructures feudals de l'ocàs romà ja formalitzades, els militars passaren a formar-ne part sota el jurament de vassallatge, que comportà la transformació del guerrer (Flori 1986: 34) des de miles cap a vassus modificant així les relacions de poder en l'estructura social (Auerbach 1996: 133). Els militars del final de l'Imperi i els guerrers-vassalls posteriors s'assimilaren sota el mot de cavallers, resultants de la culminació del procés de transformació social i cultural que té com a època de referència l'Edat Mitjana (Flori 1998: 14).

La transformació social s'aprecia des de tres tipus de documents escrits: les cançons de gesta, els romans courtois i les novel-les de cavalleries. No obstant això, cal tenir presents els textos religiosos a causa de la importància que pren el cristianisme en l'època medieval i per la necessitat intrínseca a cada creença de fondre's amb la societat, cosa que només es pot aconseguir mitjançant una difusió intensa i acurada des de dues vessants. D'una banda, hi ha l'aproximació idiomàtica i, d'altra, el sincretisme o l'assimilació d'elements anteriors, comuns i entenedors per al poble.

La figura del guerrer s'associa amb els territoris bàrbars a causa de la influència del substrat germànic que perviu al procés de romanització. La força de l'oralitat, en aquestes cultures nòrdiques, és un element a tenir en compte, així com la dificultat de la transcripció dels documents escrits en uns idiomes simples i toscos cap a altres molt més rics i acurats (Borges 1966), adaptats per religiosos familiaritzats amb el conreu de l'escriptura.

Les identitats dels protagonistes de l'Evangeli -dels evangelis- es confonien amb els herois autòctons creant una de les primeres contraposicions entre els significats de civilització i de cultura (Elias 2011: 61). La figura de Cynewulf, a l'hora de tractar la imatge de Jesús en la Visión o el sueño de la cruz, ho fa descrivint-lo com un jove guerrer. A més, la dels deixebles era representada com la d'uns guerrers «tristes en el atardecer» (Borges 1966: 8) per la necessitat d'aproximar l'Evangeli als feligresos, fent-lo entenedor fins i tot en els aspectes quotidians.

La identitat laica dels guerrers és un argument a què recorren, de manera constant, els medievalistes, tot i que, a partir dels textos, és difícil de demostrar (Flori 1989: 41). El procés de conversió cristiana és progressiu i s'inicia des de les elits per expandir-se cap a la resta de la societat bàrbara de les antigues fronteres de l'Imperi Romà, on la supervivència era la prioritat per a una població guerrera en essència. Els nobles foren més permeables a la cristianització a 
causa de l'educació i de la vida en la cort (Le Goff 1999: 40 i ss.). La cavalleria s'identifica amb la guerra i s'associa a unes eines que són les armes i els cavalls. Amb l'evolució es va donar pas a un nou estament que arribà a confondre's amb la noblesa (Flori 1986: 43 i ss.).

\section{EL FINAL DEL TEMPS}

La crisi marcada per l'Apocalipsi afectà la mateixa estructura del sistema (Duby 2010) i comportà la reestructuració social de la qual va nàixer el cavaller. A l'estructura medieval d'oratores, bellatores i laboratores, el cavaller és l'element transversal que lliga les diferents peces d'una societat estanca. Es tracta d'un bellator però, pel seu origen, es pot considerar un laborator que feia de l'ús de les armes una manera de viure. Des de l'evolució, se li atorga un estatus social privilegiat respecte de la seua procedència que arriba, en ocasions, a confondre's amb la noblesa. Respecte a la relació amb els oratores, hi ha la contribució a les croades i a la integració dels homes d'armes al si de les comunitats eclesiàstiques. Però els soldats necessiten de guerres i la funció dels cavallers queda desvirtuada a mesura que les fronteres s'expandeixen i els territoris hostils passen a ser terres domesticades.

El guerrer resultant de la Reforma gregoriana esdevingué súbdit del Papa quan Jerusalem estava presa pels infidels i la fi del món s'aproximava. Preparar la tornada del Messies era l'ocasió ideal per porgar les penes i, així, romandre al seu costat in saecula saeculorum. Els ordes religiosos hi participaren recollint ànimes i expandint els dominis cristians. Jerusalem va ser conquistada el 1099; la tornada del Messies estava preparada i els cavallers protegien pelegrins i conquerien noves terres alhora que porgaven les penes. Els bellatores s'aproximaven als oratores, com ens demostra l'exemple del mateix Ramon Llull, fins al punt que alguns d'ells varen aconseguir la licentia predicandi per la butlla papal d'Alexandre III. Altra Guerra Santa fou a la Península Ibèrica i de nou La chanson de Roland és una mostra de la incorporació d'aquesta tasca a l'èpica i de la transformació d'un conflicte bèl-lic en un de religiós.

Els ordes mendicants aproximaren el discurs moral al teològic $i$ van ser un exemple amb la donació de béns entre els rics que volien incorporar-se a una vida d'austeritat i sentit religiós. Es formaren els ordes dels cavallers del Temple i de Sant Jaume, ja assimilats pel papat amb més butlles alhora que apareixien noves congregacions laiques de creients, generalment pobres, que es relacionaven en comunitats per viure d'una manera més pròxima a Crist, o les figures individuals dels ermitans, resultants del pensament agustinià ${ }^{2}$.

Guillem de Tours, al llarg de la seua obra, tracta tres temes que centren l'atenció del lector quant a l'aspecte de la religiositat a l'Edat Mitjana: la decadència, tant en el llenguatge com en el contingut del text, la violència, $i$ els batejos que canvien el curs de la història, com el «Del sizé rey de France qui

${ }^{2}$ El mateix sant Agustí narra al Llibre V de Confesiones que anà a un racó de l'hort per aillar-se i, així, retrobar-se amb Déu. 
ach nom Xalderich $»^{3}$ (Cingolani 2008: 112). Borges estudia la tradició literària germànica i demostra la cristianització dels relats (Borges 1966) en coincidir amb el moment de la seua escriptura, ja passat l'any mil. La conversió cristiana dels territoris germànics és una evolució des de la proximitat de l'antic territori llatí i que finalitza -quant al canvi religiós de les elits- a l'inici del segon millenni, amb l'arribada a Islàndia i amb la consegüent influència del cristianisme en la construcció dels relats de cavalleries, de la zona germànica continental, inexistent al seu inici oral i poètic (Flori 1998: 8).

La crisi que assotà l'estable model clàssic de vida s'aprecia en Ramon Llull des de quatre aspectes molt resumits: l'abandó de les rimes, l'escriptura en català, l'argumentació racional i l'adaptació de l'ordre de cavalleria als nous temps. La literatura és la transmissora de la transformació alhora que manté la visió efectista de les narracions cavalleresques en la difusió del canvi social i cultural. El cavaller, com a element transversal de la societat, era una icona i un referent a l'hora de difondre qualsevol missatge. Ramon Llull, al Llibre de l'orde de cavalleria, observant el canvi social, ja avança la nova etapa (Llull 1998: 170).

\section{ELS ERMITANS A LA LITERATURA CATALANA DEL S. XV}

En les novel-les catalanes de cavalleries més importants, dos són els models d'ermitans que s'hi troben i, en ambdós casos, es tracta d'antics cavallers que, per una raó o altra, han deixat les armes per dedicar-se a la vida contemplativa o a la conversió d'ànimes. L'exemple de l'ermità de Tirant lo Blanc s'oposa al de Curial e Güelfa però, en ambdós casos, allò evident és la presència dels eremites i, d'altra banda, que són un exponent de l'evolució dels models laics anteriors. La causa del canvi cap a la «Devotio Moderna» es pot trobar en l'assimilació agustiniana transmesa per fra Antoni Canals i per fra Eiximenis, i la influència del missatge d'aquests dos religiosos en el pensament de l'època, la novetat del qual radica en «l'esperit pràctic» (Hauf 1990: 19-55).

Tirant, a l'inici del seu viatge cap a Anglaterra, ensopega de casualitat amb un ermità que llegia un llibre de cavalleries. Martorell, a més, narra les aventures d'un valerós noble, de nom Guillem de Varoic, que un dia va sentir la necessitat d'anar a la Terra Santa i, en tornar, esdevingué ermità (Martorell 1990: 6) com a colofó d'una existència digna però buida de contingut. A causa de la guerra contra els sarraïns, aquest cavaller va abandonar la vida de passió per tornar a l'acció, en veure que era necessari als seus (Martorell 1990: 15-16). L'exemple de Guillem de Varoic podria estendre's a la resta de cavallers que, allunyats de la tasca primera de lluita i protecció per a la qual foren concebuts, ja arribat el temps del seu ocàs, intentaren donar sentit a la seua vida i a la seua feina (Flori 2004: 263). Tirant és altre exemple de la crisi en què van entrar els guerrers quan la seua tasca es limitava a combatre en duels, per l'honor i per deport.

${ }^{3}$ Equivocació i canvi del nom de Xalderich pel de Clodoveu, segons consta en la nota de mateix autor de l'edició (Cingolani 2008: 111). 
Els elements a considerar, quant al personatge de l'ermità, són els següents: el conflicte intern que intenta porgar a Terra Santa, l'allunyament del món, la tornada per servir el rei i el Déu, l'aprenentatge del seu fill, el rencontre amb la solitud i la influència sobre Tirant, a qui veu noble d'esperit. L'antecedent de Guillem de Varoic és Guillem d'Orange que, com narra la cançó de gesta Guillaume au Court Nez, es fa monjo ermità ${ }^{4}$ després de la mort de la seua esposa (Masip 1999: 35-36).

Al llarg de Curial e Güelfa, Sanglier apareix en dues ocasions ben diferenciades. La primera, al Llibre II, ho fa sota la figura d'un brau cavaller, temut per tots i odiat per molts que s'enfronta a un jove inexpert. Curial, guanyador del duel, continua la seua vida de cavaller victoriós mentre que Sanglier desapareix de la novel-la com ho fan els derrotats (Anònim 1998: 181 i ss.). No obstant això, Sanglier retorna al Llibre III, com a ermità, a la Terra Santa, on agraeix a Curial que l'ajudés a «entrar en la vida i abandonar la mort», a causa de la derrota del duel. La vida, per Sanglier, ha estat trobar Déu i lloar-lo com es mereix; la mort era la vida mundanal de pecat i de vici.

Els elements a tenir en compte a l'hora d'avaluar el personatge, de manera cronològica, són els següents: la fama de guerrer ferotge, l'abandó de la cavalleria per dedicar-se a l'oració, el canvi de l'occident per l'orient, la conversió en pescador d'ànimes i la poca influència que exerceix sobre Curial. El frare intenta instruir el jove perquè abandone les armes, perquè encara és a temps, $\mathrm{i}$ l'adverteix que es troba guiat pel mateix diable i que no gaudeix de cap alegria ni gratitud (Anònim 1998: 247-248).

L'exemple de l'assimilació agustiniana per part de Ramon Llull (Hauf 1990: 34) converteix els ermitans en elements aliens a la societat. No obstant això, el canvi de funció, des de soldat de Món cap a soldat de Déu, no s'acaba d'assimilar amb plenitud (Flori 1986: 3) i el cavaller continua sent un referent col-lectiu que ha transitat des de l'oralitat fins a la novel-la, adaptant-se a cada situació, a cada transformació, a cada època i a cada territori. Des de l'inici, laic i guerrer, nòrdic i bàrbar, fins a la cristianització de les seues acaballes, croat i monjo, religiós i vassall, la figura del cavaller ha estat present durant gairebé mil anys.

\section{LA RELIGIOSITAT COM A SÍMPTOMA DEL DECLIVI}

Els canvis en la percepció anterior i posterior a l'any mil analitzats per Le Goff (Le Goff 1999: 154-166) i per Duby (Duby 2010) necessiten del referent intel-lectual i literari de sant Agustí (Llibre XX secció 19 de Civitas dei) quan tracta l'Apocalipsi, ubicada entre l'estada terrenal de Crist i els mil anys posteriors, fins a la segona vinguda del Messies. Aquest mil-lenni pertanyia a l'Església, amb Satanàs captiu i amb la progressiva victòria de l'Evangeli. No obstant això, l'arribada del mil-lenni comportà una crisi que les traduccions de sant Jeroni a la Vulgata llatina s'encarregaren de difondre. El canvi de mentalitat,

${ }^{4}$ Sobre aquesta història versa la cançó de gesta que passa a ser un referent per a escrits posteriors. (Anònim 1867). 
una volta superat el període de crisi finisecular, comportà la modificació de la raó de ser dels cavallers (Auerbach 1996: 21). Ramon Llull mostra en el Llibre de l'orde de cavalleria un cavaller sotmés a Déu que va un pas més enllà en la seua evolució, des del guerrer del final de l'Imperi fins a la relació de vassallatge: de vassall del noble passà a convertir-se en noble mateix i, finalment, en vassall de Déu $u^{5}$ I aquesta última modificació duia implícita la Guerra Santa com a porga dels pecats i com una finalitat última del sistema de vassallatge. La decadència és evident des del moment en què el cavaller, l'antic guerrer bàrbar, admet el pes del pecat i l'acte de fe (Nietzsche 2007: 33).

Aquest declivi el descriu Ingmar Bergman ${ }^{6}$ quan tracta la crisi des de dues perspectives: d'una banda, la incidència de la pesta i el pessimisme existencial del canvi d'època i, d'altra banda, la total desubicació del cavaller que retorna de la croada sense saber quin sentit hi ha al darrere de la vida i dels actes humans. En els capítols de Curial e Güelfa i de Tirant lo Blanc vinculats als ermitans també es palesa aquest sentiment contraposat a les edats dels guerrers, bé en la comparació entre Curial i Sanglier o bé entre l'ermità i Tirant. D'una banda, hi ha el jove impetuós que busca engrandir la seua fama mitjançant les aventures i, d'altra banda, hi ha el guerrer cansat i derrotat, bé per les batalles, bé per la vida mateix, que busca recolliment.

Fer valer la prosa per novel-lar els fets i les aventures dels cavallers ja és, en si mateix, un símptoma de decadència. La novel-la és una narració burgesa i, com a tal, lligada a la ciutat i al seu model de vida, on els nobles $i$ altres persones vinculades als feus s'identificaven amb els relats de cavalleries a causa de llur procedència (Huizinga 1967: 65). La línia narrativa que començava amb les cantinel-les arriba a l'ocàs amb la prosa. La urbanització de la vida allunya el burgés del seu avantpassat cultural (Auerbach 1996: 133) i aquest fet se suma a la decadència del cavaller mateix.

\section{ELS ERMITANS ROMÀNTICS A LA LITERATURA EUROPEA: ZARATHUSTRA I EMPÈDOCLES}

El Romanticisme està vinculat a l'Edat Mitjana i a la recerca del jo que Hegel interpreta com a principi de la subjectivitat interna (Hegel 1989: 382-383) i el vincula a la autonomia i a la llibertat romàntiques a partir de l'honor subjectiu, l'amor i la fidelitat, en la línia ja creada de les afinitats romàntiques i les medievals (Hegel 1989: 408). La figura de l'ermità retorna amb força al Romanticisme amb Així parlà Zarathustra i La mort d'Empèdocles. Guerrers de les paraules i de les idees, Nietzsche i Hölderlin, foren víctimes del seu temps com ho van ser els seus protagonistes. La inadaptació als nous temps és el detonant d'aquestes conductes que coincideixen, a més, amb èpoques de canvis.

Hölderlin ens presenta un Empèdocles allunyat de la civilització, buscant la reflexió que, per excés, deriva en hostilitat, entesa com a llibertat per l'autor.

\footnotetext{
5 A partir de la Reforma gregoriana, al segle XI, s'entén com a vassall del papa.

${ }^{6}$ Det sjunde inseglet [El seté segell], 1957.
} 
Com en el cas del rei ermità de Tirant, Empèdocles torna a la civilització quan li ho demana la família, però l'amor i l'honor no són suficients. Al poc de temps, l'ermità retorna a l'Etna amb la decisió de romandre-hi per sempre. Mentre Empèdocles opta per la reclusió i el recolliment, el seu adversari en l'obra s'oposa al destí (Hölderlin 1993: 185). La contraposició dels models és evident, així com la de l'altre ermità il-lustre de nom Zarathustra; el personatge creat per Nietzsche que recull el testimoni directe del drama de Hölderlin i que esdevé un complement de l'anterior. Al contrari que Empèdocles, Zarathustra sí que torna a la civilització amb la intenció de canviar-la (Nietzsche 1986: 23) en una mena d'aventura quixotesca. L'ermità de Tirant també ho fiu per ajudar el seu poble i el seu rei. Sanglier no retornà a la civilització, tot i que volia modificar-la, des de la seua atalaia, intentant influir sobre els cavallers. Empèdocles i Zarathustra retornaren a la cova per iniciar, així, el seu darrer viatge: el primer, cap al cràter de l'Etna i, el segon, no se sap cap a on; però, ambdós guiats per la natura.

\section{MARAGALL I EL PERÍODE ROMÀNTIC}

Nietzsche està present a l'obra de Maragall, tant per la influència exercida sobre l'escriptor català com per la seua precocitat a l'hora d'assimilar-lo i explicar-lo a les columnes de premsa. El seu pensament arribà a Catalunya per via francesa i va marcar la joventut del poeta fins al punt d'inculcar-li una actitud vitalista que trencava els esquemes de la societat burgesa de Barcelona. El primer a parlar seriosament de Nietzsche, a Catalunya -i a la resta de l'estat-, fou Maragall. En els articles del Diario de Barcelona i de L'Avenç, l'escriptor va exposar el pensament nietzschià al gran públic creant una tensió que acabà en censura ${ }^{7}$. La influència del filòsof acompanyà Maragall tota la vida fins a les últimes creacions, ja impregnades per Novalis, on encara és palesa l'empremta vitalista més pragmàtica front a un final ple d'incertesa que només crea que dubtes (Maragall 1998: 814-815). A banda del coneixement de l'obra de Nietzsche, aquesta es podia ampliar a altres dos autors alemanys com Novalis i Goethe. De Nietzsche, la influència apunta cap a la llibertat dionisíaca que es pot entreveure en la reivindicació de la vida i de la seua expressió sense censura. De Novalis, la influència pren el caire religiós, mentre que, de Goethe, aquesta deriva cap a la tradició neoclàssica.

La vida que desprén Nietzsche en cada escrit és benvinguda fins que arriba a les pinzellades violentes d'alguns dels seus passatges ${ }^{8}$. Interpreta la voluntat com l'espurna de la vida, la frescor de la paraula i l'expressió espontània9 . Quant a la representació, Maragall abraça Novalis, molt més vinculat a la influència de les emocions per descriure la natura, que acaba d'alliberar-lo de la

7 L'article «Frederic Nietzsche» escrit a 1893 per al Diario de Barcelona, redactat originalment en castellà, no fou publicat a causa de la censura eclesiàstica, tot i que es publicà a L'Avenç, traduït al català, sota el títol de «Nietzsche» i el pseudònim de Panphilos.

8 «Per què vessar la sang inútil? / Dins de les venes, la vida és sang: / vida pels d'ara i pels que vindran; / vessada és morta» (Maragall 1929: 102).

9 «Adalaisa, tu que ets tan vividora / i que els ulls tens plens de voluntat...» 
racionalitat excessiva i l'aproxima cap a allò que denomina «la paraula viva», que s'intueix tant en la prosa com en la poesia. En aquest cas, el batec de la fe conforma la imatge del poeta sobre la realitat que l'envolta, descrita amb la llibertat del moment d'inspiració.

El concepte de vida de Maragall s'oposa al d'altres escriptors de l'època, com Alcover, que opten per la tècnica i la feina minuciosa, influïts per autors més classicistes. Alcover observava, en l' «espontaneïtat incontrolada» de l'estil de Maragall, la proximitat del caos. A més, entre les influències del mallorquí hi havia la d'autors francesos que feien servir, en menor mesura, eixa perniciosa espontaneitat mentre se centraven, majoritàriament, en el conreu literari i poètic (Fuster 1988: 68). Maragall, per contra, ja entenia la paraula com un element transformador del caos quan afirmava que, quan es fa servir, «del caos en surt la llum» (Maragall 1978: 35), en referir-se al primer element de la creació del Gènesi.

La poesia forma part de la realitat humana, tot i ser un camp de la literatura. I és en aquest aspecte on Maragall pren el referent de Novalis en els dos darrers terços d'El comte Arnau (Terry 2000: 166). La poesia és l'eina més humana per a la descripció de la realitat; és inherent a cada ésser humà i no sols una facultat dels literats. A partir d'aquest pensament, qualsevol persona esdevé un poeta potencial i el procés de creació és l'acte en què ho plasma -la performance (Lord 2000: 13)-; per tant, el resultat de donar forma a aquesta qualitat humana esdevé un poema.

La reacció davant de l'obra comporta una mena de calfred, o estremiment, que esdevé un punt d'inflexió en el criteri maragallià emprat per qualificar la poesia i l'art. Per entendre una obra com a excepcional, aquesta, en la seua composició, havia de contenir eixes espurnes de creativitat immediata que l'allunyava de la voluntat creadora, racional i meditada, mentre l'apropava a la instantaneïtat de vida ${ }^{10} \mathrm{com}$ a part d'un procés més subjectiu, romàntic, $\mathrm{i}$ vinculat al diàleg espiritual.

El Romanticisme canvia el focus cultural europeu. La base il-lustrada, situada en l'antiguitat grega, passa a ser múltiple i variada perquè se situa l'indret on s'aplica l'estudi, tenint en compte les característiques històriques i culturals de cada poble. Maragall veia, en aquest moviment, les petjades del Naturalisme que derivà cap al Modernisme (Fuster 1998: 36). La interpretació de l'Edat Mitjana resultà rellevant en la construcció de la identitat dels diferents pobles que formen Europa. La literatura de l'època, així com els ideals cavallerescos i les tradicions folklòriques, passà a ser objecte d'estudi i d'anàlisi. D'entre els mites es buscaran pilars sòlids des d'on (re)construir la identitat de cada indret i la llengua esdevindrà el fil conductor que uneix l'època pretèrita amb el present dels pobles. La reivindicació d'allò propi i diferenciador, en el moment en què s'universalitza, deixa de ser excloent perquè cada poble es troba en la mateixa situació i pot buscar la identitat fent servir les eines apropiades i aplicar-les a la pròpia evolució. Per tant, eixe determinisme inicial es pot interpretar

10 «La "paraula viva" afluirà als llavis -a la ploma- del poeta en descàrregues il-luminades, intermitent, interjeccional». «"L'única poesia autèntica és la fragmentària", afirmà Maragall. "La resta és retòrica".» (Fuster 1988: 45). 
com a una base comuna d'anàlisi i reflexió vinculada a l'acceptació de les altres cultures (Herder 2007: 14-15).

La llibertat de creació i de pensament romàntics activa la capacitat d'interpretar a partir de substrats diferents i obri la possibilitat d'investigar i d'aplicar els elements diferenciadors que augmenten la riquesa i la varietat (Maragall 1978: 72). A més, la llibertat romàntica trenca la pressió racional -imitadora- exercida sobre l'art, tot i que en indrets com França, la capa il-lustrada forma part de la seua idiosincràsia (Staël: 1890). Aquesta tendència, en el nostre àmbit, contraposa els poetes Alcover i Maragall. Però Alemanya, construïda sobre estructures feudals, és més procliu a les noves tendències, i aquesta recerca de la identitat pròpia com a fonament i vincle del col-lectiu té la base en els residus culturals medievals, abans oblidats o menyspreats, que encara hi romanen. La foscor medieval es transforma en llum, les llengües pròpies encapçalen l'expressió del poble, el passat oblidat torna a la memòria i, finalment, la natura i la cultura s'uneixen per conformar l'individu.

Per a Herder, la religió és imprescindible i la fonamenta en la mateixa Europa medieval (Herder 2007: 123-124), tot i la diversitat de criteris en la seua interpretació. Nietzsche entén superada l'etapa cristiana perquè adverteix un afebliment de l'home que l'inutilitza per avançar, amb decisió, cap al futur (Nietzsche 2007: 33). Ell proposa un nou cristianisme basat en els elements anteriors al Nou Testament; aquells que feien de l'home un ésser fort i convençut de la seua tasca vital.

Maragall interpreta la religió com un espai de llibertat i de vida que trenca les línies rigoroses il-lustrades i resulta una manera individual d'interpretar la realitat. El Cant espiritual és l'exemple de la fluctuació que mou el poeta entre la vessant més terrenal i la del més enllà (Fuster 1988: 52). Maragall té el valor d'endinsar-se en allò més allunyat de la seua creença i la capacitat per extraure'n els elements positius sense capgirar-ne l'essència. I l'exemple n'és l'aproximació i l'exploració de la filosofia nietzschiana, el mètode de la qual descriu a l'inici del seu article de L'Avenç del 15 de juliol de $1893^{11}$. El Cant espiritual és l'exemple del pragmatisme mundanal que impregna el pensament de Maragall (Maragall 1998: 814-815), però allò que realment motiva la seua existència és el discórrer de la vida... Dubta que s'hi puga superar, en altra vida -al més enllà-, això que ha estat gaudint, en tan gran mesura, en aquesta.

\section{L'HOME EXCEPCIONAL EN NIETZSCHE I EN MARAGALL: EL COMTE ARNAU}

L'arribada del primer mil·lenni comportà una crisi que les traduccions de sant Jeroni a la Vulgata llatina, influïda pel referent de sant Agustí1 ${ }^{12}$, s'encarre-

11 «Que n'hi ha de maneres d'entendre la vida, de sentir-la! Nosaltros, homes d'avui, hem d'abarcar totes les que puguem, tastar-les totes, que, ben tastades, no n'hi ha ni una on no s'hi trobi quelcom del gust, de l'aroma immortal que és el gran secreet de les coses» (Maragall 1978: 93).

12 Llibre XX, secció 19, de Civitas Dei. 
garen de difondre. Amb el segon mil·lenni retorna sant Agustí sota la visió de Zarathustra i la victòria del bé sobre el mal, emmarcada en el nou Evangeli nietzschià i que mou els fils humans del comte Arnau ${ }^{13}$. L'arrancada d'aquest període, que transita des de la Guerra Francoprussiana fins a la I Guerra Mundial, crea una inestabilitat i una incertesa que marquen el canvi de mil.lenni com va ocórrer a l'Edat Mitjana.

El Naixement de la Tragèdia és el fonament teòric amb què Nietzsche vol modificar el classicisme des de la seua essència primera, fent servir l'element dionisíac per contradir l'ordre i l'equilibri il-lustrats. El filòsof opta per l'esperit de la música a l'hora d'explicar l'origen de la Grècia clàssica i centra el seu declivi en la figura del mateix Sòcrates. A partir d'aquesta premissa, es proposa el drama musical wagnerià per regenerar Alemanya des d'una llibertat dionisíaca ofegada sota l'excessiva racionalitat ${ }^{14}$.

El mil-lenarisme i l'empenta de les noves formes culturals i polítiques obrin la porta al canvi i a la regeneració, bé rupturista, bé continuista. Nietzsche opta per la primera perquè l'entén com una tornada a l'inici; a la situació anterior al mal socràtic. En la seua visió de l'Apocalipsi, el Satanàs atenenc duu massa temps entre els humans i cal tornar-lo a encadenar, altres mil anys, fins que es regenere el món. L'enviat, nascut d'entre els homes, no és altre que el sobre home. Also sprach Zarathustra reivindica que cada home conscient haurà de crear-se a partir de la llibertat radical que comporta l'esperit dionisíac i que suposa l'equilibri front a la racionalitat apol-línia. Però, tot i que Nietzsche recerca l'essència en l'Antiga Grècia, el Romanticisme es troba arrelat a l'Edat Mitjana i la creació de la identitat comuna s'intueix en la literatura i el folklore popular; per donar-li cos i esperit, hi ha la música de Wagner. Maragall recrea l'home excepcional, lliure i existencialista ${ }^{15}$ a El comte Arnau; una poesia que recull la tradició catalana medieval i que quasi es converteix en drama musical (Terry 2000: 174). Amb clares referències al sobre home d'arrel nietzschiana, la poesia de Maragall enllaça l'esperit dionisíac i l'elitisme aristocràtic de l'alemany amb la tradició medieval catalana, mentre el monòleg de Zarathustra es troba més vinculat a pronosticar la necessària arribada del sobre home en una mena d'evangeli del jo (Nietzsche 1986: 27). El vincle del sobre home amb la terra i amb la voluntat apareix en els dos textos; en ambdós casos, l'home viu la vida i defuig la mort ${ }^{16}$, com explica el Cant Espiritual.

13 « Que és llarga l'eternitat! / Només fa mil anys que corre / el comte Arnau... i està cansat. $/$ ¡Que és llarga l'eternitat!» (Maragall 2010: 55).

${ }_{14}$ Pedrell va proposar a Maragall de crear un drama musical a partir d'El comte Arnau, tot i que, al final no es va realitzar l'adaptació (Terry 2000: 173-176).

${ }^{15} \mathrm{La}$ incursió d'aquest mot, tot i que es tracta d'una definició posterior a l'època del poeta, no és altra cosa que una xicoteta llicència causada pel lligam que demostra Maragall entre el ser $\mathrm{i}$ l'existir. El comte s'aferra a la vida perquè no confia en una vida més enllà de la terrenal que, en el rerefons, és allò que marca la vida i el pensament dels guerrers: «Doncs: ser home sobre home/ ser la terra palpitant. / Seràs roure, seràs penya, / seràs mar esvalotat, / seràs aire que s'inflama, / seràs astre rutilant, / seràs home sobre home, / perquè en tens la voluntat» (Maragall 2010: 48).

16 «Viure, viure, viure sempre: / no voldria morir mai; / ser com roure que s'arrela / i obre la copa a l'espai» (Maragall 2010: 47). 
En un clar exemple de l'evolució del relat, la poesia de Maragall ens mostra el trànsit del guerrer en la mesura en què l'autor camina des de Nietzsche fins a Novalis, passant per Goethe. Si fem atenció a dita evolució, apreciem que en la mateixa narració d'El comte Arnau hi ha les pautes que s'han anat seguint en el present estudi. Primerament, hi ha el fet històric de l'existència del comte i dels elements que l'envolten. Després, hi ha la transformació que sofreix i que fa d'aquesta persona un personatge amb una vida digna de ser narrada. En tercer lloc, hi ha la llegenda oral transmesa entre generacions que comporta la presència del relat en el temps. Aquesta antiga llegenda pren forma de cançó i passa a ser una part més de l'imaginari col-lectiu i s'assimila a la tradició de tot un poble, fins que, al final, assoleix la forma escrita ${ }^{17}$.

El procés que fonamenta el text arriba fins al Romanticisme, on es plasma definitivament i l'empremta del temps i dels espais transitats roman present. La popularitat del mite queda palesa en la difusió del clam ${ }^{18}$ i el seu pas cap a la lírica popular i col-lectiva. L'anacronisme del fenomen s'observa en el pagament de les soldades, però també s'hi pot observar en la seua invocació, quan el simple fet de clamar l'esperit fa que retorne allò que semblava vell i superat.

La història del comte Arnau se situa en el desencís del guerrer condemnat a l'administració i a l'ordre, a la família i a la pau. L'amor, però, n'és altra causa, on el cavaller s'hi troba en una fase anterior a la humanista, de Curial o de Tirant, que admeten la fidelitat amorosa i la practiquen. Arnau torna enrere, sense lligams, en una acció romàntica que se li podria atribuir al mateix Goethe, a Faust. El personatge de Maragall recerca, als orígens de la cavalleria, la llibertat i l'ètica del guerrer, partint des del moment de canvi cap a una tasca per a la qual no s'ha estat concebut. L'essència de la vida el converteix en un personatge anacrònic d'un món immers en el cristianisme que diferencia el bé del mal atenent a principis morals. El preu de la llibertat és l'ailllament i la por. D'altra banda, la comtessa descobreix una ànima en pena, molt diferent a l'ànima lliure amb què es contempla el protagonista. La redempció d'Arnau, influïda per Novalis (Terry 2000: 166), s'inicia des de la pietat, amb l'entrada de ses filles al convent, mentre son pare -l'ànima- continua lliure i amenaçadora.

La devoció cristiana va esmenar les cançons populars fins al punt d'allunyar les gestes dels cavallers de l'imaginari col-lectiu ${ }^{19}$. El Comte Arnau va perdre el sentit d'existir en el cant fins que l'amor romàntic d'una jove desconeguda fiu que l'ànima del guerrer es redimira i descansara en pau. Que «l'heroi no existeix sinó en el cant» (Le Goff: 1982: 156) explica aquesta última evolució en el tancament del poema de Maragall i, alhora, torna a l'assimilació cristiana dels guerrers. El trànsit de la poesia, per tant, evoluciona al ritme de la cavalleria, on la llibertat radical de Nietzsche es transforma amb la recerca de la redempció cristiana de Novalis.

17 «Alguns diran que la sentiren; / altres ni en tenen cap record, / quins oblidaren, quins ni la ö̈ren... / La cançó ha mort, la cançó ha mort. / Jo d'una vella la afollada/pel pes dels anys, la vaig sentir / ja sense to, a glops, trencada» (Maragall 2010: 82-83).

18 «totes les veus de la terra / se dispersen udolant» (Maragall 2010: 56).

19 «La cançó ha mort, la cançó ha mort» (Maragall 2010: 82). 


\section{CONCLUSIÓ}

Nietzsche apuntava ja, al Naixement de la tragèdia, l'existència d'un vincle directe entre la tradició popular medieval i l'essència dionisíaca grega (Nietzsche 2007: 45). De la poesia de Maragall podem extraure, en primer lloc, que el poema plasma la realitat de la tradició oral i, per tant, comporta eixa recerca de la identitat col-lectiva que té el guerrer com a element característic. En segon lloc, que per alliberar el comte Arnau de la càrrega pejorativa causada pel canvi que va arrossegar el cavaller cap a l'ocàs, el relat deu desvincular-se dels judicis de valor associats al cristianisme per tornar a l'estat primari, dionisíac, on l'oralitat i la música eren la vida ${ }^{20}$.

L'esperit dionisíac transita cap a l'ordre apol-lini -socràtic- amb la cristianització del cant popular i només s'allibera d'aquesta excessiva racionalitat quan el cant torna a les seues arrels, virginals i indoctes, que naixen de la veu viva. Si Arquíloc va introduir la cançó popular en la literatura, la seua acceptació popular la va causar la unió d'allò dionisíac amb la part apol-línia (Nietzsche 2007: 70-74). La poesia de Maragall resulta d'un procés semblant al d'Arquíloc i, situat al Romanticisme -diguem-ne Modernisme-, recerca els mites populars de l'Edat Mitjana.

La figura del cavaller medieval es pot considerar una icona per dos aspectes diferents. Primer, perquè està present a la major part de la mitologia popular de l'Edat Mitjana i és un vincle entre qualssevol dels estaments socials de l'època. I, segon, perquè sota la seua imatge hi ha l'element transversal, laic, lluitador i lliure que es transmet cada vegada que s'anomena allò dionisíac. L'Evangeli de Zarathustra reclamava l'acció del sobre home perquè la religió, la racionalitat i el pacte social afeblien l'ésser humà i el món necessitava d'una regeneració. El guerrer, exemple de la individualitat i l'acció, esdevé amb Nietzsche un referent universal.

El comentari de Nietzsche sobre el gravat de Dürer El cavaller, la mort $i$ el dimoni (Nietzsche 2007: 173) és una breu i clara referència a la posició del guerrer envers la resta de la societat i una explicació de la seua conducta. El comte Arnau abandona la cursa sense fi per refugiar-se en la pietat perquè hi ha un moment en què són massa feixucs els judicis i el temor. Els vassalls no entenen el seu concepte de justícia, Adalaisa no ha comprés la seua manera d'entendre l'amor, la família ha estat porgant les penes heretades del comte entre la soledat i la religió... El guerrer se sent derrotat a causa del dubte esdevingut dels judicis populars fins que una jove i pura donzella capgira l'esperit adulterat de la cançó i la torna dolça, buida de tota intenció i de tota por; ella canta sense jutjar ni condemnar. El cavaller es redimeix quan la interpretació torna als seus orígens (Flori 1986: 41), des d'on actuava per impulsos i on la victòria era el senyal de la justícia i la llibertat mundana movia cada acció.

${ }^{20}$ «Cantant, cantant nasqué la infàmia, / i descantant la redempció: / el comte Arnau tenia l'ànima / a la mercè d'una cançó. / El que la mort tanca i captiva, / sols per la vida és deslliurat: / basta una noia de veu viva/per redimir la humanitat» (Maragall 2010: 83). 
Nietzsche es troba present a la base teòrica d'El comte Arnau i, des de la perspectiva que ens dóna el temps, es pot concloure que l'única manera d'alliberar el filòsof alemany de la càrrega a què el sotmet el pensament socràtic és el simple fet de llegir-lo amb la mirada neta de la jove del poema de Maragall -o, millor dit, desllegir-lo. Perquè l'espasa d'Arnau és, a la fi, la ploma de Nietzsche.

\section{BIBLIOGRAFIA}

Agustín Confesiones, Biblioteca virtual Miguel de Cervantes, edició digital [Consulta: 10/05/2015].

Anònim (1867) Guillaume d'Orange. Le marquis au court nez. Chanson de geste du XIIe siècle, P. N. Van Kampen, Amsterdam.

Anònim (1998) Curial e Güelfa, Barcelona, Edicions 62.

Auerbach, E. (1950) Mimesis: la representación de la realidad en la literatura occidental, Barcelona, Seix Barral.

Borges, J. L. (1966) Literaturas germánicas medievales, Libros Tauro, edició digital http://biblio3.url.edu.gt/Libros/borges/Medievales.pdf [Consulta: 20/05/2015].

Cingolani, E. M. (2008) Libre dels reis, València, Universitat de València.

Croce, B. (1996) Historia de Europa en el siglo XX, Barcelona, Editorial Ariel.

Curtius, E. R. (1995) Literatura europea y Edad Media Latina, 2 vol., Madrid, Fondo de Cultura Económica.

Duby, G. (2010) El año mil: una nueva y diferente visión de un momento crucial de la historia, Barcelona, GEDISA.

Elias, N. (2011) El proceso de la civilización, Madrid, Fondo de Cultura Económica.

Flori, J. (2004) Chevaliers et chavalerie au Moyen Âge, Paris, Éditions Hachette.

Flori, J. (1986) L'essor de la chevalerie. XI ${ }^{e}$ XII ${ }^{e}$ siècles, Genève, Droz.

Flori, J. (1998) La chevalerie, Paris, Éditions Jean Paul Gisserot.

Fuster, J. (1988) Literatura catalana contemporània, Barcelona, Curial.

Hauf, A. (1990) D'Eiximenis a sor Isabel de Villena. Aportació a l'estudi de la nostra cultura medieval, Barcelona, IFV, PAM.

Hegel, G. W. F. (1989) Lecciones sobre la estética, Madrid, Ediciones Akal.

Herder, J. G. (2007) Filosofía de la historia para la educación de la humanidad, Sevilla, Espuela de Plata.

Hölderlin, F. (1993) La mort d'Empèdocles, Barcelona, Quaderns Crema. 
Huizinga, J. (1967) El otoño de la Edad Media, Madrid, Selecta Revista de Occidente.

Le Goff, J. (1982) El orden de la memòria. El tiempo como imaginario, Barcelona, Ediciones Paidós Ibérica.

Le Goff, J. (1999) La civilización del occidente medieval, Barcelona, Paidos.

Llull, R. (1988) Llibre de l'orde de cavalleria, Barcelona, Barcino.

Lord, A. B. (2000) The singer of tales, Cambridge, London, Stephen Mitchell and Nagy, ed.

Maragall, J. (2010) El comte Arnau, Barcelona, Edicions 62.

Maragall, J. (1978) Elogi de la paraula i altres assaigs, Barcelona, Edicions 62.

Maragall, J. (1929) Obres completes, Barcelona, Sala Parés Llibreria.

Maragall, J. (1998) Poesia. Edició crítica, Barcelona, Edicions de La Magrana.

Martorell, J. (1990) Tirant lo Blanc, València, Arts Gràfiques Soler.

Masip, L. (1999) Ermitans a la literatura medieval, Barcelona, Edicions de l'Abadia de Montserrat.

Nietzsche, F. (1986) Así habló Zarathustra. Barcelona, Editorial Planeta.

Nietzsche, F. (2007) El nacimiento de la tragèdia, Madrid, Alianza Editorial.

Riquer, M. (1952) Los cantares de gesta franceses, Madrid, Editorial Gredos.

Schopenhauer, A. (2004) Fragmentos para la historia de la filosofia, Madrid, Ediciones Siruela.

Staël, M. (1890) De l'Allemagne, Paris, G. Charpentier et Cie Éditeurs.

Terry, A. (2000) La poesía de Joan Maragall, Barcelona, Quaderns Crema. 